\title{
Article
}

\section{Do orthotic walkers affect knee and hip function during gait?}

Richards, Jim, Payne, Katherine, Myatt, Darren and Chohan, Ambreen

Available at http://clok.uclan.ac.uk/11227/

Richards, Jim ORCID: 0000-0002-4004-3115, Payne, Katherine, Myatt, Darren and Chohan, Ambreen ORCID: 0000-0003-0544-7832 (2014) Do orthotic walkers affect knee and hip function during gait? Prosthetics and Orthotics International .

It is advisable to refer to the publisher's version if you intend to cite from the work. http://dx.doi.org/10.1177/0309364614546525

For more information about UCLan's research in this area go to http://www.uclan.ac.uk/researchgroups/ and search for <name of research Group>.

For information about Research generally at UCLan please go to http://www.uclan.ac.uk/research/

All outputs in CLoK are protected by Intellectual Property Rights law, including Copyright law. Copyright, IPR and Moral Rights for the works on this site are retained by the individual authors and/or other copyright owners. Terms and conditions for use of this material are defined in the policies page.

\section{CLoK}

Central Lancashire online Knowledge www.clok.uclan.ac.uk

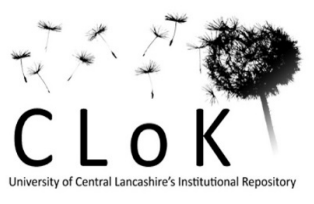


DO ORTHOTIC WALKERS AFFECT KNEE AND HIP FUNCTION DURING GAIT? 


\section{ABSTRACT}

Background: Much previous research on orthotic walkers has focussed on their ability to offload structures in the foot and ankle, however little is known about their effects on lower limb mechanics. This study aimed to determine effects of two orthotic walkers on the biomechanics of the knee and hip joints compared to standardised footwear. Technique: Ten healthy participants walked under three conditions; Walker A (Össur,IS), Walker B (DJO Global,CA) and Standardised footwear (Hotter,UK). Kinematic and kinetic data were collected using a Qualisys motion analysis system and force plates. Significant differences were seen in hip kinematics and knee moments between walkers and standardised footwear and in knee kinematics between Walker $A$ and standardised footwear. Discussion: Both walkers show significant kinematic and kinetic differences compared with standardised footwear; however Walker A appeared to produce greater deviation, including potentially damaging greater hyperextension moments at the knee.

\section{Word Count: 143 words}

\section{Clinical Relevance:}

Further research is needed into the effects of orthotic walkers on knee and hip joint mechanics, which should help to inform future designs of walker, with greater focus on obtaining a more normal gait pattern. Word Count: 35 words 


\section{BACKGROUND AND AIMS}

Orthotic walkers are frequently used in clinical practice in the management of various pathologies; though the predominant use of these orthoses is in the management of diabetes related foot health (1). Orthotic walkers and Total Contact Casts (TCC's) work by redistributing the plantar pressure more evenly over the midfoot and TCC techniques are increasingly being replaced by the removable orthotic walker (2). Orthotic walkers allow early weight bearing while providing protection; they are adjustable and removable for examination, facilitating exercise and early intervention in the event of a problem and reducing the need for orthopaedic technicians (2). Reduced hospital stay, less rehabilitation sessions and early intervention together with ease of application and adjustment mean orthotic walkers are becoming the cost effective solution (3) to conservative management of a range of acute and chronic conditions.

Walkers have been shown to be more effective than traditional fibreglass casts in reducing lower leg muscle activity (4) as well as promoting a faster return to baseline activity (3). Early mobilisation with the use of orthotic walkers affords a better clinical outcome in terms of ankle function, bone strength and faster bone healing $(2,5)$, with individuals showing improved quality of life through a shorter hospital stay and faster return to activities of daily living and sport $(2,5,6)$. In contrast the use of the TCC, to immobilise the lower limb is decreasing, due to the requirements of an experienced technician and its associated joint, muscle and skin related undesirable outcomes (7). Several studies have explored use of orthotic walkers and their effect on plantar 
pressure distributions (8), however limited attention has been given to the study of kinematics and kinetics when wearing such orthoses $(2,9)$. Whilst these studies imply that orthotic walkers elicit less adverse effects (2) than TCC's, the true impact of these walkers during longer term use requires further investigation (10). The aim of this study is to explore the short-term effect of two designs of orthotic walkers on hip and knee kinematics.

\section{TECHNIQUE}

\section{Participants}

Ten healthy participants (6 Males, 4 Females; $37.1 \pm 12.1$ years) were recruited from university staff and student populations. All participants reported to be free from any pain or pathology of the lower limbs or spine at the point of testing. All data collection conformed to the Declaration of Helsinki and volunteers gave written informed consent prior to participation. The study was approved by the Built, Sport and Health Ethics Committee (XXXXXXXXXX XXXXXXXXX XXXXXXXXXX, XX).

\section{Procedure}

Passive retro-reflective markers were placed on the lower limbs and pelvis using the Calibrated Anatomical System Technique (CAST) to allow for segmental kinematics to be tracked in 6-degrees of freedom. Markers were positioned on the anterior superior iliac spine, posterior superior iliac spine, greater trochanter, medial and lateral femoral epicondyle, medial and lateral malleoli, the head of the 1st metatarsal, the head of the 5th metatarsal, the dorsum of the foot and the calcaneus or equivalent placement over 
these landmarks on the walker. Additionally clusters of four non-colinear markers were attached to the body segments of the shank and thigh and on the anterior plate of the walker. Kinetic data were collected at $200 \mathrm{~Hz}$ using four AMTI force plates. Kinematic data were collected using a ten camera infra-red Oqus motion analysis system (Qualisys medical AB, Gothenberg, SE) at $100 \mathrm{~Hz}$. All participants were asked to walk along a 10 metre walkway under three conditions; (a) Standardised footwear \{with No Orthosis\} (Hotter, UK) (b) Walker A (Rebound ${ }^{\mathrm{TM}}$ Air Walker, Ossur, IS) and (c) Walker B (Aircast ${ }^{\circ}$ FP Walker, DJO Global, USA) [Figure 1]. Five repetitions for each condition were performed in a randomised order. All walkers were applied in accordance with the manufacturer's instructions on the left foot.

Anatomical frames were defined by landmarks positioned at the medial and lateral borders of the joint, from these right handed segment co-ordinate systems were defined. The kinematics were calculated based on the cardan sequence of XYZ. Raw kinematic and kinetic data were exported to Visual3D (C-Motion Inc., USA). Kinematic and kinetic data were filtered using fourth order Butterworth filters with cut off frequencies of 6 and $25 \mathrm{~Hz}$, respectively. Knee and hip angles and moments and centre of pressure were exported and repeated measured ANOVAs were performed on maximum, minimum and range values using SPSS v20 (IBM,NY, USA).

\section{Results}

The two walkers showed a slight increase in the amount of knee flexion during stance phase. Significant differences were also seen between walking with standardised 
footwear and Walker A, and between the two walkers with Walker A showing a greater transverse plane range of motion during stance phase, (Table 1A). A trend towards a significant difference was seen between walking in standardised footwear and Walker A, for peak hip extension during stance phase (Table 1A). Though the average walking speed for both Walkers was notably smaller than when walking with standardised footwear, the differences were not significant $(P=0.099)$.

Significant differences in peak knee extension moments were seen between all conditions with Walker A showing the highest knee extension moment followed by Walker B, and in the peak knee flexion moments between the two walkers. Significant reductions in peak knee adduction moments were seen when walking with both walkers compared with standardised footwear (Table 1B). Hip extension moments also showed significant differences between Walker A and both Walker B and standardised footwear (Table 1B).

No significant differences between walking with standardised footwear and the two walkers for Centre of Pressure Velocity during stance phase (Table 2).

\section{DISCUSSION}

A slight increase in the amount of knee flexion was seen during stance phase when wearing the both walkers, however there was a significantly greater flexion moment when walking with the Walker A compared with Walker B. The increased knee flexion moment during loading response may be attributed to the difference in the rocker profile under the heel during the loading response phase (Figure 1). 
A trend towards a significant difference was seen between walking with standardised footwear and Walker $\mathrm{A}$ for peak hip extension angle and significant differences in peak knee and hip extension moments were also seen between all conditions with the Walker A showing the highest knee extension moment and the lowest hip extension moment. Despite there being no significant difference in walking speed, an increased knee flexion moment during loading response suggests that either the angle of tibial inclination or the movement of the centre of pressure under the rocker sole could be responsible. This increase in the moments being exerted at the knee could have damaging complications to the internal structures of the knee.

Significant differences were also seen between walking with standardised footwear and the two walkers for peak knee adduction during stance phase, however no differences were seen between the two walkers. Differences were also seen between walking with standardised footwear and Walker A and between the two walkers in the transverse plane range of motion with Walker A showing a greatest amount of rotation. As these orthotic walkers can be prescribed over an extended period of time, for instance, over a period of four weeks in conservative treatment of Achilles tendon rupture $(11,12)$, further investigation is warranted on the long term effects of these results.

No significant differences were seen between any of the conditions for centre of pressure velocity during stance phase indicating that both walkers were able to produce a smooth forwards progression of the ground reaction forces. The differences 
seen may be related to the rocker sole profile and/or the tibial inclination angle of the walkers as this is the only major technical difference between the walkers (Figure 1).

\section{Summary}

- Both walkers showed significant differences compared with standardised footwear, in a sample of ten healthy individuals however Walker A appears to produce the greatest deviation. This is particularly noteworthy in knee flexion, knee extension moments and hip extension moments which could be damaging over long term usage.

- The differences between walkers may be attributed to the subtle differences in rocker profile and tibial angles.

- It is clear from this study that further research is required with a greater number of individuals, in order to explore the effects of orthotic walkers on the knee and hip joint mechanics. This should in turn help to inform future designs of walker, with a greater focus on obtaining a more normal gait pattern.

\section{DECLARATION OF CONFLICTING INTERESTS}

The authors would like to thank DJO global for supplying the Walkers. The authors received no financial or other reward to undertake this research and there is no conflict of interest in relation to the research.

Word Count: 1420 words 


\section{REFERENCES}

1. Nagel A, Rosenbaum D. Vacuum cushioned removable cast walkers reduce foot loading in patients with diabetes mellitus. Gait \& Posture 2009; 30(1):11-15.

2. Pollo FE, Gowling TL, Jackson RW. Walking boot design: a gait analysis study. Orthpedics 1999;22:503-7.

3. Boutis K, Wilan AR, Babyn P, Narayanan UG, Alman B, Schuh S. A randomized, controlled trial of a removable brace versus casting in children with low-risk ankle fractures. Pediatrics 2007; 119(6):e1256-63.

4. Kadel NJ, Segal A, Orendurff M, Shofer J, Sangeorzan B. The efficacy of two methods of ankle immobilization in reducing gastrocnemius, soleus, and peroneal muscle activity during stance phase of gait. Foot and Ankle International 2004;25:406-409.

5. Egol KA, Dolan R, Koval KJ. Functional outcome of surgery for fractures: A prospective, randomised comparison of management in a cast or a functional brace. The Journal of Bone and Joint Surgery 2000;82-B:246-9.

6. Simanski CJ, Maegele MG, Lefering R, Lehnen DM, Lehnen DM, Kawel N, Piess $\mathrm{P}$, Yucel N, Tiling T, Bouillon B. Functional treatment and early weight bearing after an ankle fracture: a prospective study. J Orthop Trauma 2006; 20(2):108-14. 
7. Boyd AS, Benjamin HJ, Asplund C. Splints and casts: indications and methods. American Family Physician 2009; 80(5): 491-9.

8. Crenshaw SJ, Pollo PE, Brodsky JW. The effect of ankle position on plantar pressure in a short leg walking boot. Foot and Ankle International 2004; 25:6972.

9. Zhang S, Clowers KG, Powell D. Ground reaction force and 3D biomechanical characteristics of walking in short leg walkers. Gait and Posture 2006; 24:487492.

10. Lin CW, Donkers NA, Refshauge KM, Beckenkamp PR, Khera K, Moseley AM. Rehabilitaiton for ankle fractures in adults. Cochrane Database Systematic Review 2012; 11:CD005595.

11. Wallace RGH, Traynor IER, Kernohan WG, Eames MHA. Combined conservative and orthotic management of acute rupturesof the Achilles tendon. Journal of Bone and Joint Surgery 2005; 86:1198-1202.

12. Khan RJ, Fick D, Keogh A, Crawford J, Brammer T, Parker M. Treatment of acute Achilles tendon ruptures. A meta-analysis of randomized controlled trials. Journal of Bone and Joint Surgery American Volume 2005; 87(10):2202-10. 
Figure 1: Showing the tibial inclination and rocker profile of (left) Walker A \{Tibial Inclincation angle: $4.3^{\circ}$, Heel Rocker Profile: $25^{\circ}$, Forefoot Rocker Profile: $\left.12^{\circ}\right\}$ (Rebound ${ }^{\mathrm{TM}}$ Air Walker, Ossur, IS), (right) Walker B \{Tibial Inclincation angle: $2^{\circ}$, Heel Rocker Profile: $22^{\circ}$, Forefoot Rocker Profile: $6^{\circ}$ \} (Aircast® FP Walker, DJO Global, USA).

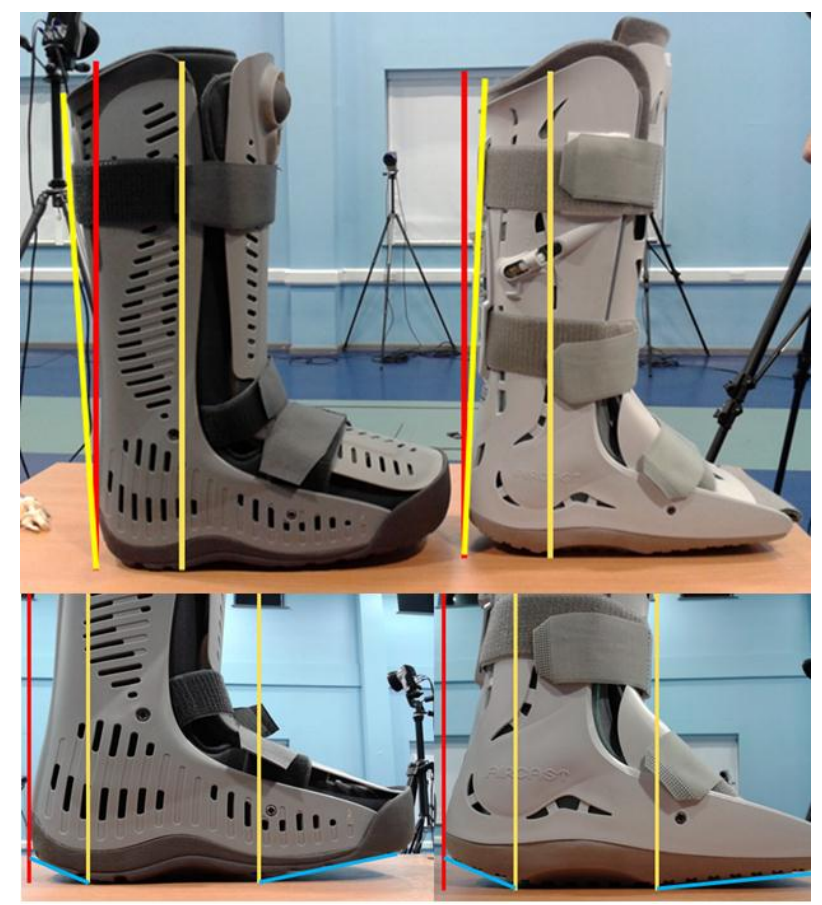


Table 1A

Knee and hip joint angles for Standardised footwear (SF), Walker A (WA) and Walker B (WB).

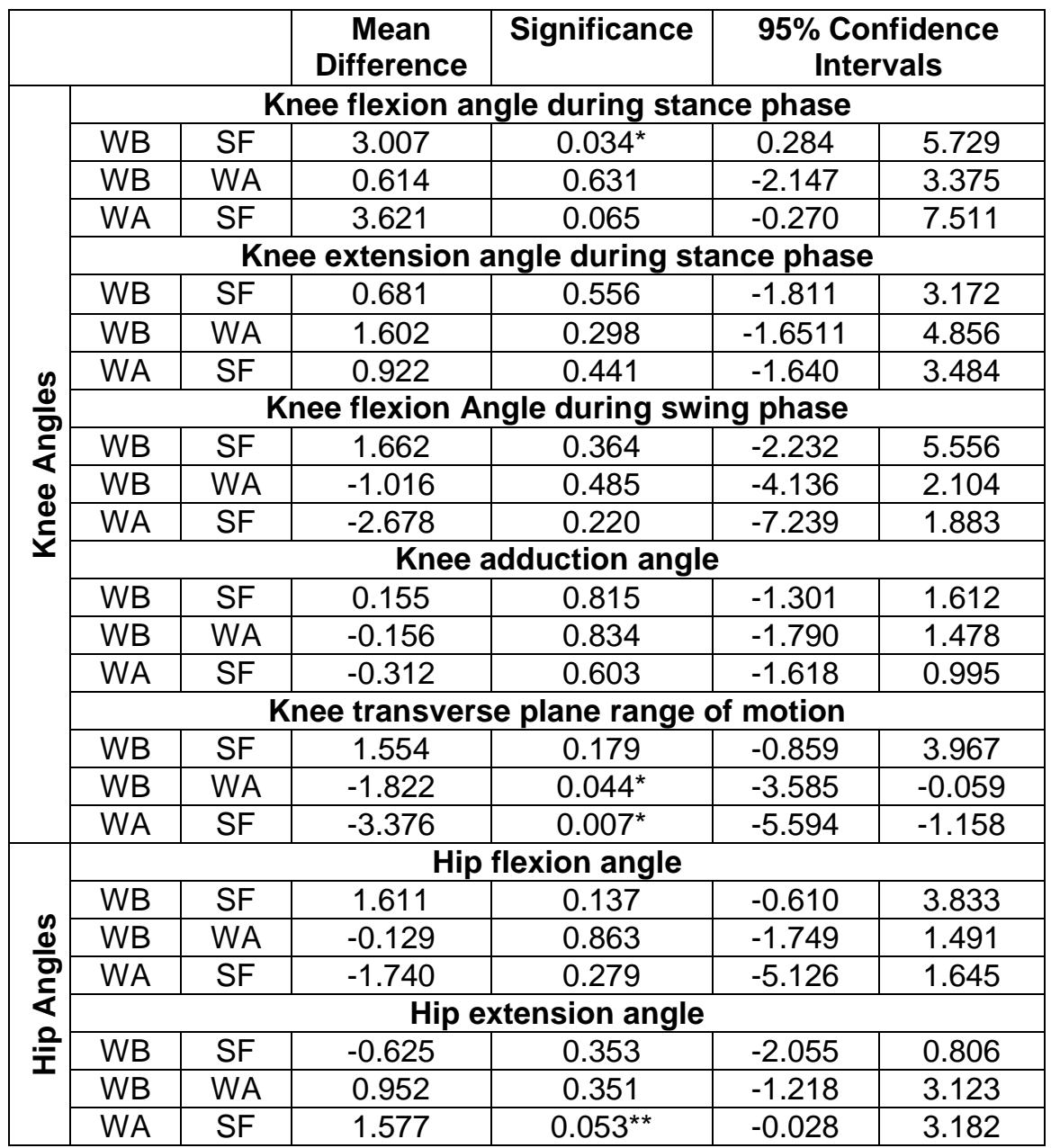

*Significant difference, **trend towards significance 


\section{Table 1B}

Knee and hip joint moments Standardised footwear (SF), Walker A (WA) and Walker B (WB).

\begin{tabular}{|c|c|c|c|c|c|c|}
\hline & $\begin{array}{c}\text { Mean } \\
\text { Difference }\end{array}$ & Significance & \multicolumn{2}{|c|}{$\begin{array}{l}\text { 95\% Confidence } \\
\text { Intervals }\end{array}$} \\
\hline \multirow{12}{*}{ 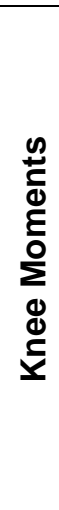 } & \multicolumn{6}{|c|}{ Peak Knee flexion moment } \\
\hline & WB & SF & 0.070 & 0.413 & -0.112 & 0.252 \\
\hline & WB & WA & -0.091 & $0.005^{\star}$ & -0.147 & -0.035 \\
\hline & WA & SF & -0.161 & 0.097 & -0.356 & 0.035 \\
\hline & \multicolumn{6}{|c|}{ Peak Knee extension moment } \\
\hline & WB & SF & -0.211 & $0.001^{*}$ & -0.307 & -0.115 \\
\hline & WB & WA & 0.130 & $0.005^{*}$ & 0.048 & 0.212 \\
\hline & WA & SF & 0.341 & $0.000^{*}$ & 0.210 & 0.471 \\
\hline & \multicolumn{6}{|c|}{ Peak Knee adduction moment } \\
\hline & WB & SF & 0.116 & $0.002^{*}$ & 0.054 & 0.179 \\
\hline & WB & WA & -0.033 & 0.121 & -0.077 & 0.011 \\
\hline & WA & SF & -0.150 & $0.002^{*}$ & -0.231 & -0.068 \\
\hline \multirow{8}{*}{ 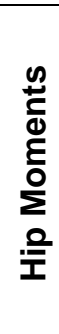 } & \multicolumn{6}{|c|}{ Peak Hip flexion moment } \\
\hline & WB & SF & -0.019 & 0.723 & -0.135 & 0.098 \\
\hline & WB & WA & -0.021 & 0.647 & -0.120 & 0.078 \\
\hline & WA & SF & -0.002 & 0.979 & -0.167 & 0.164 \\
\hline & \multicolumn{6}{|c|}{ Peak Hip extension moment } \\
\hline & WB & SF & 0.071 & 0.079 & -0.010 & 0.153 \\
\hline & WB & WA & -0.050 & $0.016^{*}$ & -0.088 & -0.012 \\
\hline & WA & SF & -0.121 & $0.006^{*}$ & -0.198 & -0.045 \\
\hline
\end{tabular}

*Significant difference 
Table 2

Centre of pressure velocity

\begin{tabular}{|c|c|c|c|c|c|}
\hline \multicolumn{2}{|c|}{} & $\begin{array}{c}\text { Mean } \\
\text { Difference }\end{array}$ & Significance & \multicolumn{2}{c|}{$\begin{array}{c}95 \% \text { Confidence } \\
\text { Intervals }\end{array}$} \\
\hline WB & SF & 0.076 & 0.260 & -0.071 & 0.224 \\
\hline WB & WA & -0.003 & 0.963 & -0.146 & 0.141 \\
\hline WA & SF & 0.079 & 0.313 & -0.093 & 0.252 \\
\hline
\end{tabular}

